\title{
Solar Cars and Energy Effiecient Management System
}

\author{
J. Koloc \& M. Šimánek * \\ Czech Technical University, Faculty of Transportation sciences, Prague, Czech Republic \\ *Corresponding author: miroslav.simanek@siemensppa.com.au
}

\begin{abstract}
This paper summarizes the basic assumptions that led to a thesis which investigates the use of high efficiency solar cells used by solar cars, with the main aim of minimizing energy consumption in such a vehicle. A solar car is special in the way that there is not only energy consumed, but also generated. This energy should be used in the most efficient way, for example with the use of a combination of different energy storages, such as high efficiency batteries and super capacitors.
\end{abstract}

KEY WORDS: Solar energy, Solar Cell, WSC (World Solar Challenge), Super cap.

\section{INTRODUCTION}

In the $20^{\text {th }}$ century there was a rapid development in industry and new computer technology. New computers that can operate faster then their forerunners along with tiny microchips allow the use of controlling processes in most technological branches. In this way technological development can reduce costs in production companies and can help them work more efficiently. On the other hand, more and more electricity is being used to fulfill the high energy demand. It is enough for us to compare the electrical house appliances used these days with those used 20 or 50 years ago to realize how much the electricity demand has increased. Without thoughtfully considering when buying new household devices that will consume more energy, we are turning into a consuming society that does not think about the surrounding environment.

It is no wonder that to be able to cover high electricity demands more energy needs to be produced- the majority of it coming from coal, gas or nuclear power stations. All these electricity producers clearly introduce a hazard for the environment. Although the efficiency of coal fired power stations has increased to about $40 \%$, for the final product delivered to the customer, which might be our homes, this number will drop to just a fraction of the energy that was originally stored in the fuel. These days there are activities by some political parties and associations that try to reduce the negative impact on our environment caused by burning fossil fuels. Unfortunately the cheapest way to produce energy still has a green card and with all honesty this can not be changed in the near future.

Technological development helps to further develop different areas of science so new technologies can be used and try to compete with the old and environmentally harmful energy producers. As an example wind, water or solar energy can be mentioned. When comparing an average-sized coal power station that can generate about $1000 \mathrm{MW}$ we would have to build approximately 200 wind power stations. On one hand this introduces high costs and also 
a large area of coverage when building such power plants, but on the other hand the fuel, wind, is there and it is free. Similarly, solar power is for free, but it is not used to the extent that it could be. The main reason is that the high price of high efficiency solar cells introduces a breakpoint in their wide utilization.

There are campaigns that try to present new technologies, such as solar power, to the public. An example of such an action would be the introduction of solar cars in a competition known as "World solar car challenge" that takes place on regular basis in Australia. This is a friendly competition where solar powered cars drive a distance of over $3000 \mathrm{~km}$ through a desert driven by the power coming from the sun. The main concern of this paper is based on a dissertation thesis, which is still being processed, considering such a vehicle and designing an onboard system that would take care of energy burned by driving and also taken from the solar energy. Different driving modes will be considered and as a result a system will be designed that will manage the energy consumption. If, for example, the profile of the track would already be known this system could optimize the energy outflow so the finish destination will be reached. Furthermore, an electrical design that possibly improves the efficiency of this vehicle will also be considered. Controlling processes that will optimize the energy consumption will be included.

\section{SOLAR CAR TECHNOLOGY}

\subsection{WSC “WORLD SOLAR CHALANGE”}

World solar challenge is, without a doubt, one of the most famous and prestige campaigns that promote alternative energy sources - in this case solar energy. The race takes place on a track which covers $3021 \mathrm{~km}$ through the Australian outback, from Darwin to Adelaide. Along the track there are 9 check points where the racing teams have to stop. The distance between those outback towns varies between 300 and $500 \mathrm{~km}$. The start of the race is in Darwin with a short presentation where the solar vehicles are introduced, and there is also some time for a chat with the members of the racing teams. The next stops are Katherine (318km), Dunmara (633km), Tennant Creek (987km), Alice Springs $(1498 \mathrm{~km})$, Cadney Homestead (2025km), Glendabo (2430km), Port Augusta $(2719 \mathrm{~km})$ and the final stop is in Adelaide after $3021 \mathrm{~km}$. Teams entering this contest have to comply with strict regulations which are limitations for the solar car construction. The main limits will be introduced:

- As already stated the solar panel area should be no more than $6 \mathrm{~m}^{2}$.

- As the race is over public roads, the cars have to adhere to the normal traffic regulations; however, there is a special note in the official regulations remarking on the tendency of drivers to take advantage of a favourable road camber in order to capture the maximum amount of solar energy.

- A minimum of 2 and maximum 4 drivers have to be registered. If the weight of a driver (including clothes) is less than $80 \mathrm{~kg}$, ballast will be added to make up the difference.

- Driving time is between 0800 and 1700 hours. In order to select a suitable place for the overnight stop (alongside the highway) it is possible to extend the driving period for a maximum of 10 minutes, and this extra driving time will be compensated by a starting time delay the next day. 
- At various points along the route there are checkpoints where every car has to pause for 30 minutes. Only limited maintenance tasks (no repairs) are allowed during these compulsory stops.

- The capacity of the batteries is limited to a mass for each chemistry (such as Lithium Ion) equivalent to approximately $5 \mathrm{kWh}$ maximum. At the start of the race, the batteries may be fully charged. Batteries may not be replaced during the competition, except in the case of a breakdown. However, in that case a penalty time will apply.

- Except for the maximum outer dimensions, there are no further restrictions on the design and construction of the car.

- The deceleration of the dual braking system must be at least $3.8 \mathrm{~m}(149.6 \mathrm{in}) / \mathrm{s}^{2}$.

\subsection{BASIC SOLAR CAR ARRAGEMENT}

The basic system arrangement of a solar car would consist of three main components the motor, where electric energy is transformed into mechanical kinetic energy, the battery (or other power source), and finally solar cells that transform energy in the light into electrical energy. In the case of the solar car the physical energy stored in the light is transformed into electrical energy and then back to mechanical energy in the form of motion. Unfortunately the present efficiency of solar cells as such is not good enough to provide a sufficient amount of energy for car momentum. There has to be a separate power source that can provide the car with additional energy.

\subsection{SOLAR CELL}

There is a large spectrum of solar cells on the market these days, however the efficiency of the solar cells differ dramatically. The common solar cells in households would have an efficiency of just about $10 \%$, whereas the most efficient cells used on space ships achieve close to $30 \%$. For solar cars very efficient solar cells also need to be used to produce more energy from a smaller area. Unfortunately those cells are produced with expensive technology and expensive materials, so the cells also introduce a very high cost. One of the market's leading developers and producers of solar cells is the company EMCORE. One of their solar cells is going to be selected for further explanation and also for energy management design and calculations. As is commonly known, a solar cell or photovoltaic cell is a device that converts light energy into electrical energy by the photovoltaic effect. A typical current-voltage characteristic of this cell type is shown in figure 1.

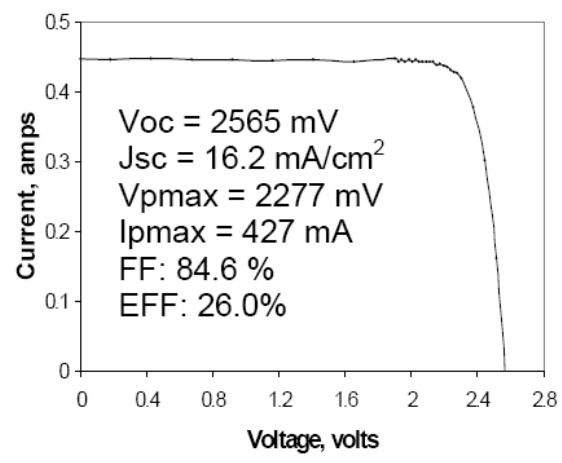

Figure 1: Solar cell current voltage characteristic 
As shown in this characteristic graph the nominal voltage of one cell is approximately $2.5 \mathrm{~V}$, which can deliver a current of about $420 \mathrm{~mA}$. This would be with an efficiency of $26 \%$. This percentage actually means how much of the provided solar energy will be converted to electrical energy.

A solar cell's energy conversion efficiency ( $\eta$, "eta"), is the percentage of power converted (from absorbed light to electrical energy) and collected, when a solar cell is connected to an electrical circuit. This term is calculated using the ratio of the maximum power point, Pm, divided by the input light irradiance $\left(\mathrm{E}\right.$, in $\left.\mathrm{W} / \mathrm{m}^{2}\right)$ under standard test conditions and the surface area of the solar cell (Ac in $\left.\mathrm{m}^{2}\right)$.

$$
\eta=\frac{P_{\lim }}{E * A_{c}}
$$

Equation 1

So the next step would be to determine how much solar energy can be expected or how much irradiance is delivered from sun. The trend measured by research institutes indicates following data for irradiance $E$ :

- In a summer day 1000 to $1050 \mathrm{Wm}^{-2}$

- In a winter day $300 \mathrm{Wm}^{-2}$

- By a clouded sky $100 \mathrm{Wm}^{-2}$

- In the night $0.01 \mathrm{Wm}^{-2}$

Considering the high solar irradiation of $1000 \mathrm{Wm}^{-2}$, a solar cell efficiency of $30 \%$ and an area of $1 \mathrm{~m}^{2}$, the possible solar energy that can be used these days transformed into electrical energy can be calculated with Equation :

$$
P_{\lim }=\eta * E * A_{c}
$$

Equation 2

According to new regulations for the WSC (World Solar Challenge) in Australia the solar cell area is limited to $6 \mathrm{~m}^{2}$ which will represent solar power of:

$$
P_{\lim }=1800 \mathrm{~W}
$$

This is the solar power output that needs to be taken into consideration when designing the energy management. This is approximately the maximum solar power that can be generated by the onboard solar cells.

Recent studies in research institutes have developed high efficiency solar cells. The world record in efficiency was reached in Germany at the Fraunhofer-Institut für Solare Energiesysteme ISE in January 2009 - a world record of $41.1 \%$ of efficiency for multijunction solar cells.

Scientists from the Frauenhofer Institute for Energy systems ISE have reached an efficiency of $41.4 \%$ in the transformation of light into electrical energy. The sun light was concentrated 454 times on a $5 \mathrm{~mm}^{2}$ plate, which is known as a multi-junction semiconductor and is made of GaInP/GaInAs/Ge".

\footnotetext{
${ }^{1}$ [5] Pro-physik : „Weltrekord: 41,1\% Wirkungsgrad für Mehrfachsolarzellen“, Internet scientific journal
} 


\section{VEHICLE MOVEMENT}

\subsection{MOVEMENT FORCES}

While the vehicle is moving, there are resistance forces that try to stop its movement. The resistance usually includes tyre rolling resistance, aerodynamic drag and grading resistance. According to Newton's second law, vehicle acceleration can be written as

$$
\frac{d V}{d t}=\frac{\sum F_{t}-\sum F_{t r}}{\delta M_{v}}
$$

Equation 3

Where $V$ is vehicle speed, $\sum F_{t}$ is the total tractive effort of the vehicle, $\sum F_{t r}$ is the total resistance, $M_{v}$ is the total mass of the vehicle and $\delta$ is the mass factor, which is an effect of rotating components in the power train.

Equation 3 indicates that speed and acceleration depend on tractive effort, resistance and vehicle mass. For investigation into further movement the movement forces displayed in figure 2 are calculated as shown in the following equations.

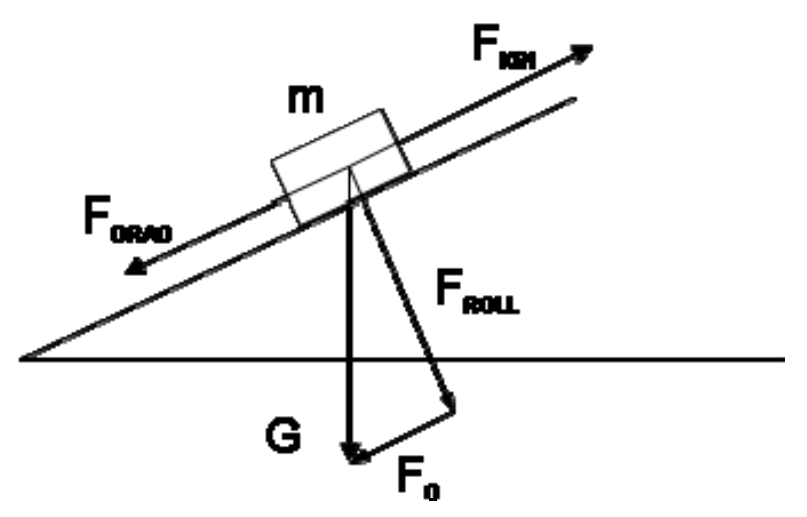

Figure 2: Ascending motion and forces

\section{Acceleration force}

When the velocity of the vehicle is changing, there needs to be a force applied which is known as acceleration force. This force will provide linear acceleration of the vehicle and is given by the equation derived from Newton's second law

$$
F_{\text {Kin }}=\mathrm{m} * \mathrm{a}
$$

Equation 4

\section{Drag Force}

Drag force is due to the friction of the vehicle body through the air. It is a function of the frontal area, shape and actually all protrusions that introduce a resistance to the air flow around the car. 
The formula for this component is:

$$
F_{\text {Drag }}=\frac{1}{2} * \rho^{*} \mathrm{v}^{2} * \mathrm{~A} * \mathrm{C}_{\mathrm{D}}
$$

Equation 5

\section{Rolling resistance force}

The rolling resistance is primarily due to the friction of the vehicle tyre on the road. The rolling resistance is approximately constant, and hardly depends on the vehicle speed. It is proportional to the vehicle weight. Another part of this force would be friction in the bearing and the gearing system. The equation is defined as:

$$
F_{\mathrm{Roll}}=m * \mathrm{~g} * \mu_{\mathrm{rr}} * \cos \alpha
$$

Equation 6

\section{Grading resistance}

When a vehicle drives up or down a slope, its weight produces a resistance force, which is always directed to the downward direction. This component either opposes the forward motion (ascending) or helps the forward motion (descending). The grading resistance force can be expressed as:

$$
F_{G}=m^{*} g * \sin \alpha
$$

Equation 7

With these equations the total tractive effort can be calculated for different driving modes as in the equation:

$$
M_{v} \frac{d V}{d t}=F_{t e}-\left(F_{\text {Roll }}+F_{\text {Drag }}+F_{G}\right)
$$

Where $d V / d t$ is the linear acceleration of the vehicle along the longitudinal direction and $M_{v}$ is the vehicle mass. The first term on the right hand side is the total tractive effort and the second term is the resistance.

When considering these calculations it is obvious that when there is going to be given a certain speed that a car should reach, then, according to design and car parameters, these forces can be determined and therefore the final resulting force. Using the forces calculation the entire mechanical power needed for certain vehicle movement can be determined as in the equation:

$$
P_{\text {mech }}=\tau * \omega=F^{*} r * \frac{v}{r}=F^{*} v
$$

Equation 9

When ignoring other friction forces and losses the mechanical power can be considered equivalent to the electrical power. The electrical power will be used to determine and design 
the power demand for the power supply and therefore the power that has to be onboard to provide enough energy for motion.

For the detailed solar vehicle design a GPS device is going to be used to record a profile of the track, time and speed. This data can be monitored, transferred to computer and finally evaluated, for example in an excel spreadsheet. figure 3 shows a short selection of data taken with a GPS device and transferred to excel.

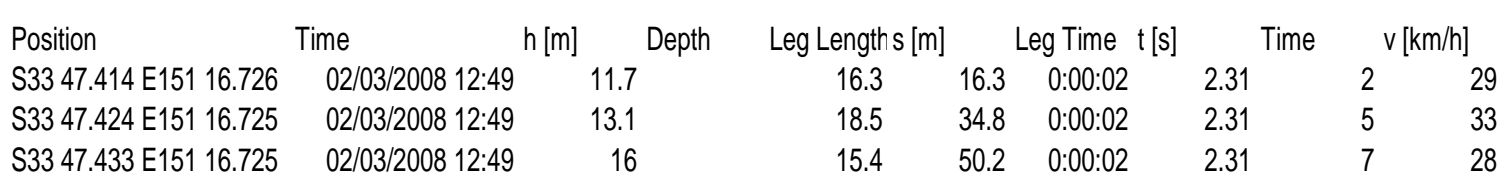

Figure 3: GPS data

Figure 4 represents an ascending track that rises from about $10 \mathrm{~m}$ to approximately $50 \mathrm{~m}$ in 50s. For this motion example the corresponding forces and power are determined.

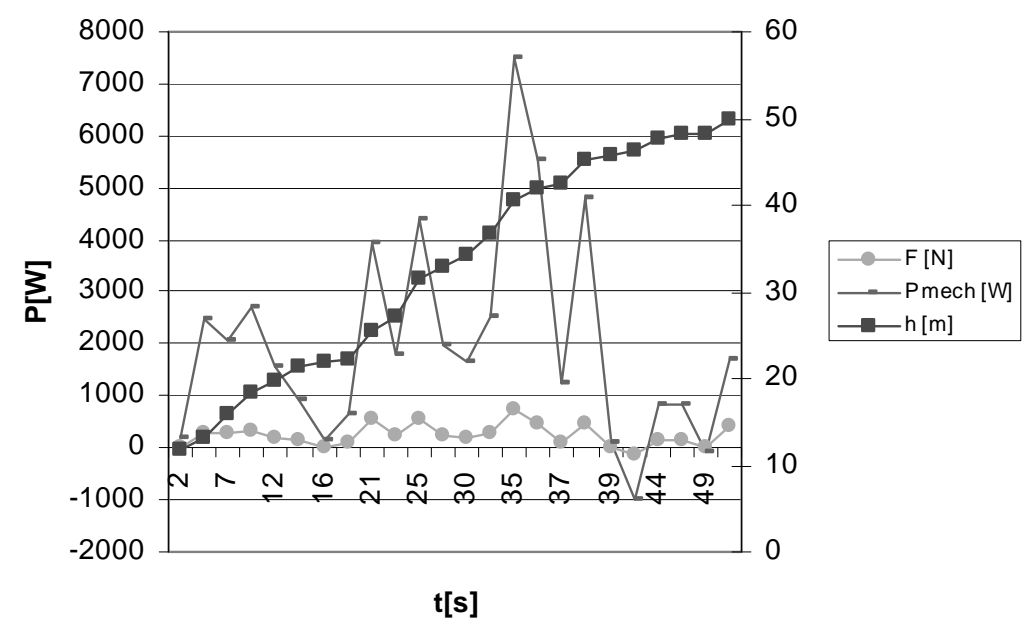

Figure 4: Power estimation

The estimation of electrical power can be used in many different ways to manage the energy onboard of the vehicle. According to the track profile and other track conditions the amount of energy or power that will be needed can be determined. Thus the power output can be controlled and can be managed, for example, to keep the power release in a desired manner it can be limited.

\subsection{DRIVING MODES}

The fundamental point for this thesis was the assumption that there are different driving modes and different driving situations that have different power requirements. The focus is going to be on special driving modes, such as acceleration, deceleration, and ascending and descending motion.

When optimizing these driving modes it is necessary to consider what energies are entering the system and what energy is going to be transformed into motion. It is understood that in the case of a solar car there is external energy from the sun, which is going to load the energy source on board of the solar car. 
In these special situations, there is much higher energy demand than even for motion. In other words it would be preferable if there would be a power source that would be active for even motion and a power source that would cover the high energy demand. This would mean a combination of a source with high energy density, such as a battery, and a source with high specific power, such as an Ultra capacitor, also known as a Super cap. To be able to fully understand the advantages and drawbacks of these, a short introduction of Super capacitors, with a comparison to the battery, follows.

\section{SUPER CAPACITOR VERSUS BATTERY}

\subsection{INTRODUCTION}

Whereas a regular capacitor consists of conductive foils and a dry separator, the Super capacitor crosses into battery technology by using special electrodes and some electrolyte. There are three types of electrode materials suitable for the super capacitor. These are: high surface area activated carbons, metal oxide, and conducting polymers.

The high surface electrode material, also called a Double Layer Capacitor (DLC), is the least costly to manufacture and is the most common. It stores the energy in a double layer formed near the carbon electrode surface. To operate at higher voltages, super capacitors are connected in series. On a string of more than three capacitors, voltage balancing is required to prevent any cell from reaching over voltage.

The energy density of the Super capacitor is 1 to $10 \mathrm{Wh} / \mathrm{kg}$. This energy density is high in comparison to a regular capacitor but reflects only one-tenth of that of the nickel metalhydride battery. This relationship is indicated in figure 3. Whereas the electro-chemical battery delivers a fairly steady voltage in the usable energy spectrum, the voltage of the super capacitor is linear and drops evenly from full voltage to zero volts. Because of this quality, the super capacitor is unable to deliver the full charge. If, for example, a $6 \mathrm{~V}$ battery is allowed to discharge to $4.5 \mathrm{~V}$ before the equipment cuts off, the super capacitor reaches that threshold within the first quarter of the discharge cycle. The remaining energy slips into an unusable voltage range. A DC-to-DC converter could correct this problem but such a regulator would add costs and introduce a 10 to 15 percent efficiency loss.

\begin{tabular}{|l|l|l|l|l|}
\hline Technology & Lead Battery & NiMH & Li-Ion & Supercap \\
\hline \hline Nominal Voltage [V] & 2.0 & 1.3 & 3.8 & - \\
\hline Max. Charge Voltage [V] & to 2.7 & to 1.7 & 4.0 & to 3.0 \\
\hline Min. Discharge Voltage [V] & 1.5 & 0.8 & 2.7 & 0 \\
\hline Specific Power [W/kg] & to $400(1200)$ & to 900 & to 1500 & $\mathbf{9 0 0 0}$ \\
\hline Specific Energy [Wh/kg] & $\mathbf{3 0}$ & 70 & 70 to 120 & 4 \\
\hline Temperature usability [ ${ }^{\circ} \mathbf{C ]}$ & -30 to 60 & -25 to 55 & $(-25)$ to 45 & $\mathbf{2} 30$ to 80 \\
\hline Charge and discharge cycles & $\sim 300$ & $\sim 1500$ & $\sim 1500(600)$ & $\sim 500000$ \\
\cline { 1 - 3 }
\end{tabular}

Figure 5: Super cap and battery comparison 
On the other hand the super capacitor has a very high specific power that can be approximately ten times higher then batteries in this comparison chart. So rather than operate them as a main battery, super capacitors are more commonly used as memory backup to bridge short power interruptions. Another application is improving the current handling of a battery. The super capacitor is placed in parallel to the battery terminal and provides a current boost on high load demands.

The charge time of a super capacitor is about 10 seconds. The ability to absorb energy is, to a large extent, limited by the size of the charger. The charge characteristics are similar to those of an electrochemical battery. The initial charge is very rapid; the topping charge takes extra time. In this design the Super cap would be charged from the solar cells. Immediately after the super cap would be discharged through a high power demand driving the logic would then be to change to battery supply and the super cap would be charged from the solar cells. Provision must be made to limit the current when charging an empty super capacitor. A resistance must be provided that will limit the charging current to the super cap. In terms of charging method, the super capacitor resembles the lead-acid battery. A full charge occurs when a set voltage limit is reached.

Unlike the electrochemical battery, the super capacitor does not require a full-charge detection circuit. Super capacitors take as much energy as needed. When full, they stop accepting a charge. There is no danger of overcharge or any 'memory' effect. The super capacitor can be recharged and discharged virtually an unlimited number of times.

Unlike the electrochemical battery, there is very little wear and tear induced by cycling and age does not affect the super capacitor much. In normal use, a super capacitor deteriorates to about 80 percent after 10 years. The self-discharge of the super capacitor is substantially higher than that of the electrochemical battery. Super capacitors with an organic electrolyte are affected the most. In 30 to 40 days, the capacity decreases from a full charge to 50 percent. In comparison, a nickel based battery discharges about 10 percent during that time.

\section{Advantages}

- Virtually unlimited cycle life - can be cycled millions of time.

- Low impedance - enhances load handling when used in parallel with a battery.

- Rapid charging -super capacitors charge in seconds.

- Simple charge methods - no full-charge detection is needed; no danger of overcharge.

\section{Limitations}

- Linear discharge voltage prevents use of the full energy spectrum.

- Low energy density - typically holds one-fifth to one-tenth the energy of an electrochemical battery.

- Cells have low voltages - serial connections are needed to obtain higher voltages. Voltage balancing is required if more than three capacitors are connected in series.

- High self-discharge - the rate is considerably higher than that of an electrochemical battery

A test was carried out at a Demo Car at Siemens VDO in Germany with an integrated starter generator that was alternatively connected to a battery (36V) and a Super capacitor (42V). Measured data for boost and regenerative deceleration are displayed in figure 4 . 


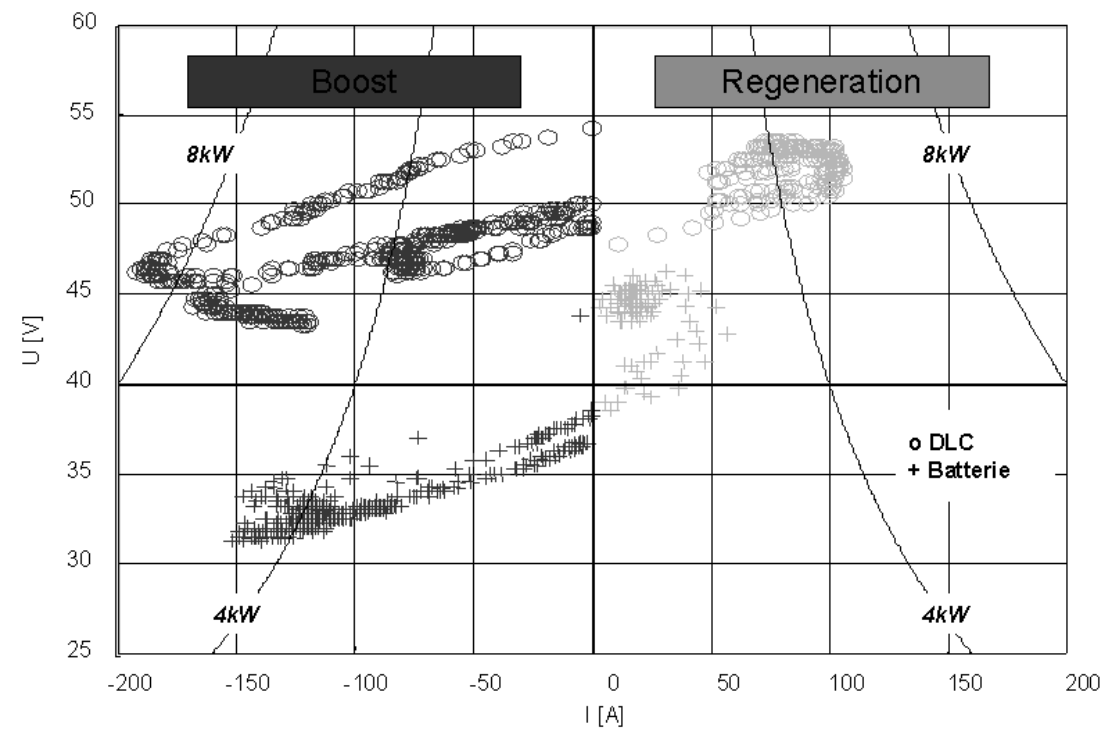

Figure 3: Comparison for boost and regenerative deceleration with Battery and Super capacitor

The measured data show that the Super capacitor can provide much higher power output during the peak discharge process. In this case the power output from the Super capacitor is almost double in comparison to the battery, comparing 8 to $4 \mathrm{~kW}$ during the boost process and 6 to $3 \mathrm{~kW}$ during the deceleration mode.

\subsection{POWER SOURCE SELECTION}

It was already mentioned that when the power consumption would exceed internally set limits then the control logic would use a different power source. This would be either a battery or capacitor. Following the same example that was used for power calculation the data can be recorded, as shown in figure 5 .

Once the power demand exceeds the power limit (for example P_lim $2000 \mathrm{~W}$ ) the power source selected is going to be the Super capacitor.

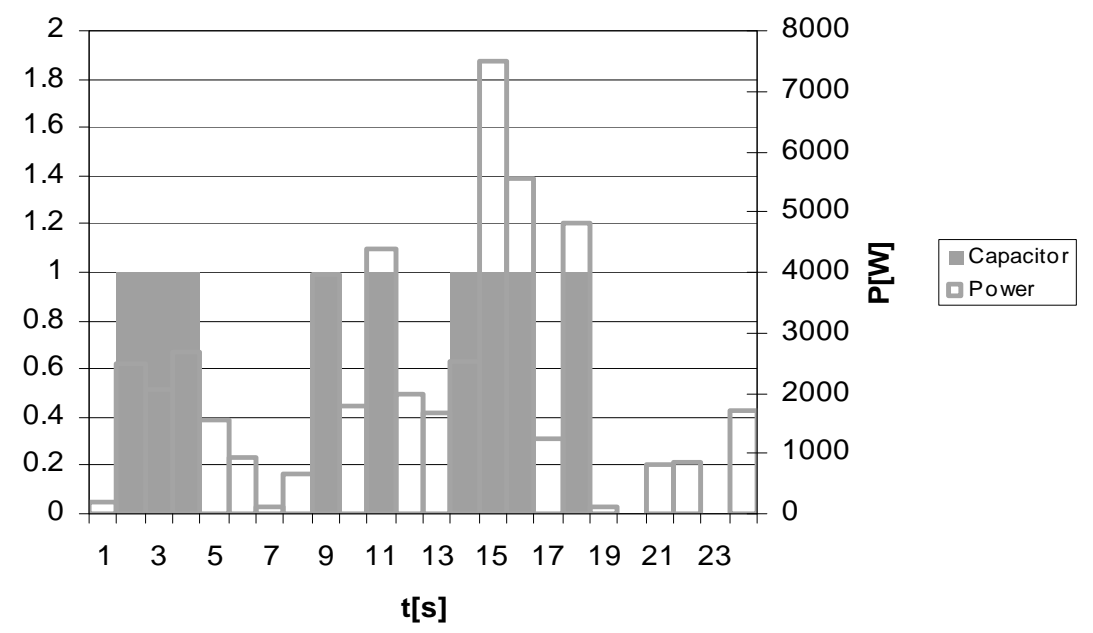

Figure 4: Power source selection (Capacitor or Battery)

When considering the charge and discharge power from the battery and capacitor, the amount of remaining charge can be calculated during their operation. So in the next example the battery will be discharged only when the needed power will not exceed 
P_lim and the capacitor will be discharged only when it exceeds this limit. This can be compared with a battery discharge only.

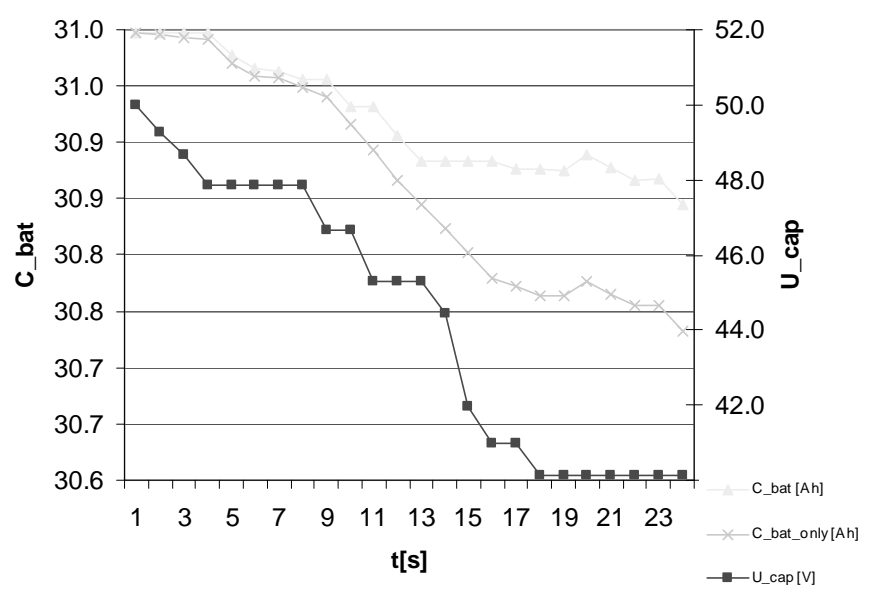

Figure 5: Comparison of different power source in operation

The capacity of energy stored in capacitor is the square proportional to the remaining voltage. In the case of the battery the capacity caused by discharging with a certain electrical current was subtracted.

Figure 6 clearly demonstrates the combination of ultra capacitor in purple, discharging from 50 to $40 \mathrm{~V}$, and the battery in yellow, where the capacity sinks from 31 to about $30.9 \mathrm{Ah}$. In the other example, where only a battery, in light blue color, was used, the battery capacity dropped from 31 to almost 30.8 Ah. This shows that by using the Super capacitor for quick discharge and also charge cycles, the capacity of the battery will remain higher. Since the charging times for the ultra capacitor are clearly shorter with minor losses, the battery capacity will experience smaller energy outflow.

\section{CONCLUSION}

The use of alternative energy resources has gained popularity with the effect of global warming and other negative effects from the common energy production using fossil fuels. Even though there is a limitation for any physical process, including the transformation of solar energy to electric, there is a necessity to use environmentally friendly resources. This concept is selecting the best qualities of different energy storages to maximize the efficiency of a solar vehicle.

Charging the Super capacitor from solar cells is more efficient then charging a battery. The reason is the low internal resistance of the Super capacitor. So the energy can be stored more efficiently in the capacitor and can be used during high power demands. This will provide additional power stored in the battery.

Further investigation will focus on the combination of such storages and the design of a basic model that can be simulated under real road conditions. The power consumption will be determined according to an active driving mode and track profile. The road information will be recorded with a GPS and imported into the simulation to allow the use of real data. The result should confirm better energy usage compared with the standard setting with only one energy storage. 


\section{REFERENCES}

[1] Douglas, H., Pillay, P.: “Sizing Ultracapacitors For Hybrid Electric Vehicles”, Internet source, University of Cape Town, Clarkson University 2008.

[2] Ehsani, M., Gao Y., Gay Sebastien, E., Emadi Ali: "Modern Electric, Hybrid Electric and Fuel Cell Vehicles: Fundamentals, Theory, and Design”, CRC Press LLC, USA 2005.

[3] Fasemi Navid, S., Sharp, R. P., Stan Mark A., Aiken J. D., Clevenger, B., Hou Hong, Q.: "Radiation-Hard High-Efficiency Multi-Junction Solar Cells for Commercial Space Applications”, Internet source, Emcore Photovoltaics, Albuquerque 2008.

[4] Maxwell Technologies: "How To Determine The Appropriate Size Ultracapacitor For Your Application”, Internet source, Maxwell Technologies, October 2004

[5] Pro-physik: „Weltrekord: 41,1\% Wirkungsgrad für Mehrfachsolarzellen“, Internet source, Fraunhofer-Institut für Solare Energiesysteme ISE, January 2009.

[6] Šimánek, M.: “Entwicklung und Aufbau eines Mikrocontroller gesteuerten Transfergates für hohe Ströme”, Diplom Thesis, Siemens Automotive, Regensburg 2002.

[7] Šimánek, M., Piáček, P.: "Solar Cars", $7^{\text {th }}$ international conference and exhibition in transport and technologies for sustainable development, Karlovy Vary: The society for Sustainable Living, 2004. 